\title{
Removal of embedded uncovered duodenal stent after 8-month indwelling
}
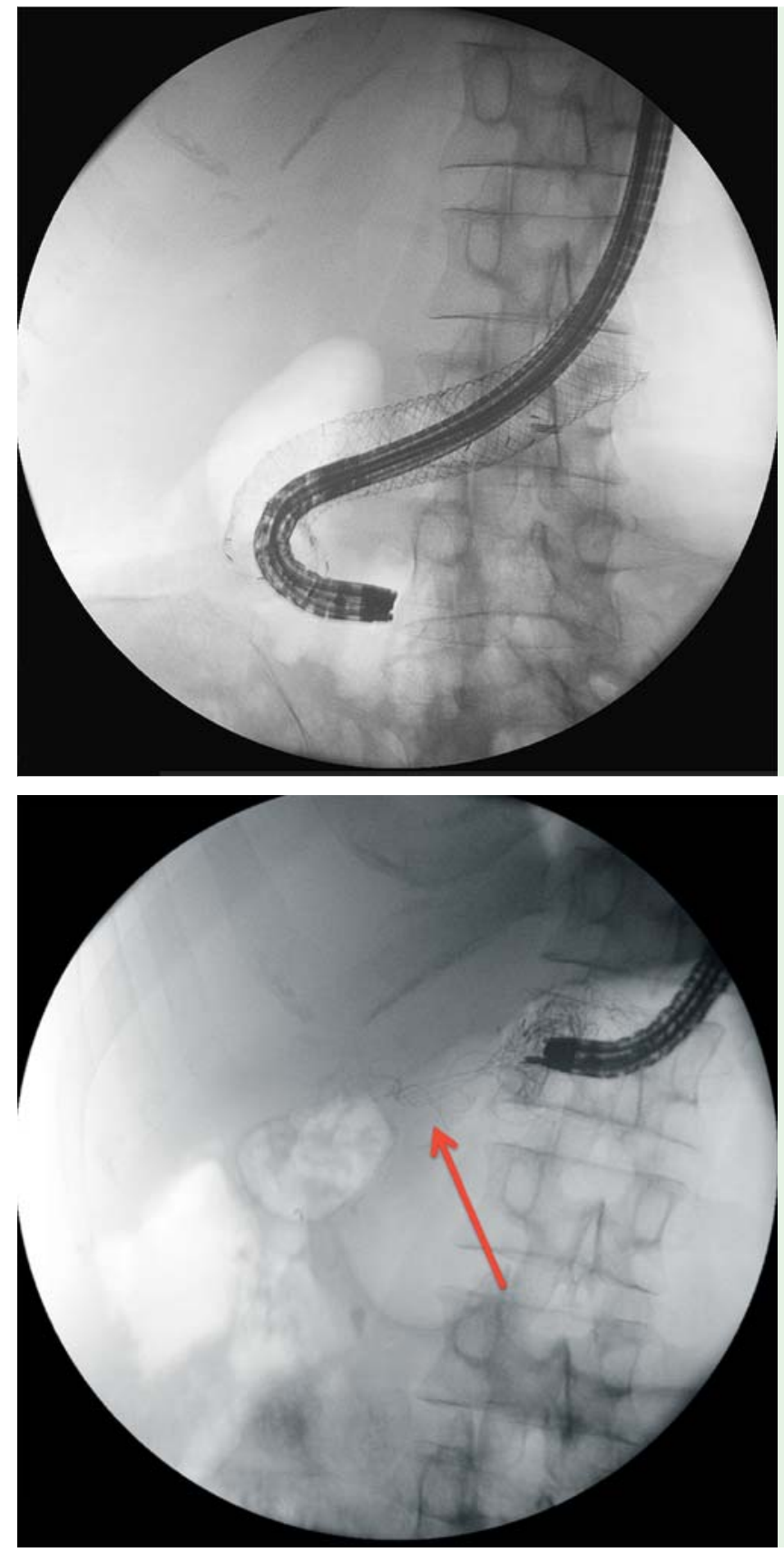

Uncovered self-expandable metallic stents (SEMSs) are used to treat malignant obstruction. Removal of SEMSs using scissor forceps, a loop cutter, and the wire-loop technique has been reported anecdotally $[1,2]$. Argon plasma coagulation (APC) is mainly used for trimming SEMSs, but is not used to attempt removal because of the risk of injury to the duodenal mucosa $[3,4]$.
Fig. 1 Uncovered duodenal Wallflex stent and partly covered Hanarostent, in place and completely unobstructed.

Fig. 3 Metallic wires of the Wallflex stent (red arrow) are still embedded in the duodenal wall, preventing removal of the stent.

We report a case of a 60-year-old man who 8 months previously had undergone placement of a duodenal stent (length $12 \mathrm{~cm}$, Wallflex; Boston Scientific, Marlborough, Massachusetts, USA), and of a second stent 1 week later $(11 \mathrm{~cm}$, partially covered, Hanarostent; M.I. Tech, Seoul, South Korea). This was done for neoplastic complete stenosis of the duodenum with other metastatic lesions also

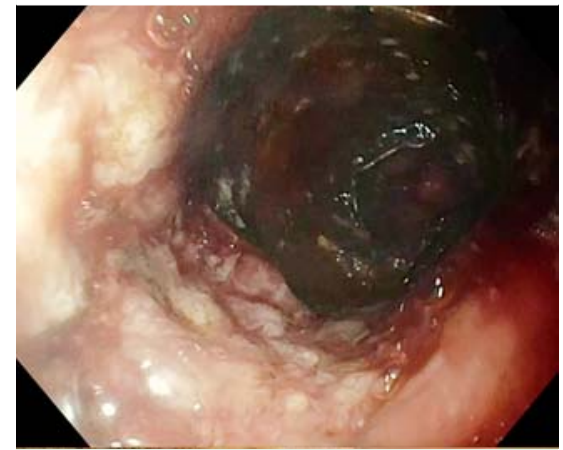

Fig. 2 Wallflex mesh completely embedded in the duodenal wall

detected at computed tomography (CT) scan. Biopsies at the time of stent placement showed lymphoma in complete remission following chemotherapy.

We decided to attempt removal of the stents. Both stents were found to be in place and completely unobstructed ( $\bullet$ Fig. 1). The inner stent was removed in multiple pieces, using a standard foreignbody forceps. The Wallflex stent was completely embedded in the duodenal wall in at least in two areas (the pyloric area and the superior flexure) ( $\bullet$ Fig. 2). APC was used to destroy overgrowth tissue. Then the distal part of the SEMS was grasped and pulled with a rat-tooth forceps, since fluoroscopy showed that some parts were still embedded in the duodenal wall ( $\bullet$ Fig.3). Overlying mucosal tissue was destroyed using APC and the SEMS was easily withdrawn, as a tangled ball of metal wires ( Video 1, $\bullet$ Fig.4). Endoscopic checking showed no complications.

The patient left hospital the following day, taking a normal diet, and continues to do well.

In conclusion we showed that in expert hands APC can be used safely, without leading to injury of the duodenal wall, in order to destroy overgrowth tissue that is retaining an uncovered stent, prior to removal of the stent. In any case, we strongly recommend that positive findings of malignancy at biopsy are mandatory before placement of uncovered stents.

\section{Endoscopy_UCTN_Code_CPL_1AH_2AD}

Competing interests: None 


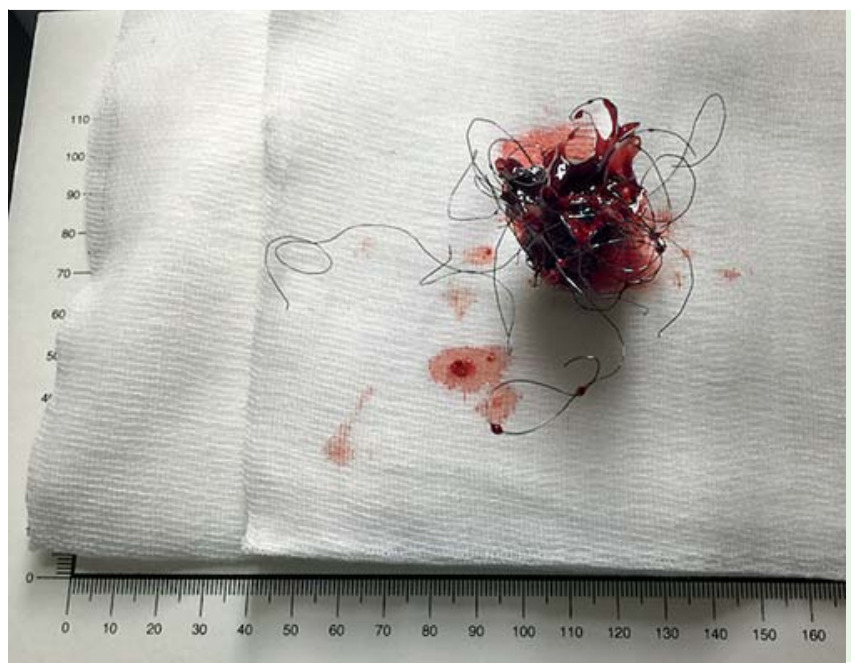

Fig. 4 The Wallflex has been completely removed, shriveled up into a tangle of metal wire.

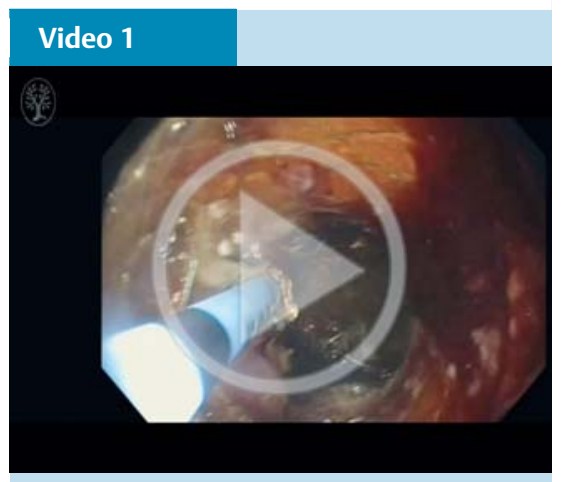

\section{Gianfranco Donatelli, ${ }^{1,2}$, Gheorghe Airinei ${ }^{1}$, Jean-Jacques Raynaud ${ }^{1}$, Robert Benamouzig ${ }^{1}$}

${ }^{1}$ Unité d'Endoscopie Interventionnelle, Hôpital Avicenne, Université Paris 13, Bobigny, France

2 Unité d'Endoscopie Interventionnelle, Hôpital Privé des Peupliers, Ramsay Générale de Santé, Paris, France

\section{References}

1 Nishi Y, Naitoh I, Nakazawa T et al. Use of a scissors forceps for the endoscopic removal of a distally migrated self-expandable metallic stent adhering to the duodenal mucosa. Endoscopy 2015; 47: E98 -E99

2 Sasaki T, Isayama H, Yoshida $S$ et al. Endoscopic trimming of a migrated gastroduodenal stent using a loop cutter and a twochannel endoscope. Endoscopy 2014; 46: E462 - E463

3 Guda NM, Freeman ML. Endoscopic transection of distally migrated biliary self-expandable metallic stents by using argon plasma coagulation: a report of 2 cases (with video). Gastrointest Endosc 2006; 63: 12 - 14

4 Vanbiervliet G, Piche T, Caroli-Bosc FX et al. Endoscopic argon plasma trimming of biliary and gastrointestinal metallic stents. Endoscopy 2005; 37: 434-438

\section{Bibliography}

DOI http://dx.doi.org/

10.1055/s-0034-1392868

Endoscopy 2015; 47: E462-E463

(c) Georg Thieme Verlag KG

Stuttgart · New York

ISSN 0013-726X

\section{Corresponding author}

\section{Gianfranco Donatelli, MD}

Unité d'Endoscopie Interventionnelle Hôpital Avicenne - APHP

125 Rue de Stalingrad

93000 Bobigny

France

Fax: +33-1-44165615

donatelligianfranco@gmail.com stroy duodenal mucosal tissue that is retaining parts of the mesh of a self-expandable metallic stent (SEMS). The stent is then removed. 